Additional Notes on Secondary Batteries

This content has been downloaded from IOPscience. Please scroll down to see the full text. 1890 Proc. Phys. Soc. London 1144

(http://iopscience.iop.org/1478-7814/11/1/306)

View the table of contents for this issue, or go to the journal homepage for more

Download details:

IP Address: 150.216.68.200

This content was downloaded on 02/10/2015 at 01:12

Please note that terms and conditions apply. 
most of the energy returus to the oscillator; only a small fraction is splashed off and sent into space. Small oscillators radiate powerfully because the quarter wave-lengths are small; whereas the slow oscillators, or alternators used commercially, radiate very little of their energy. The exact law of variation of intensity of radiation with distance was rather complicated, but the theory had beeni completely worked out by Stokes in 1848 .

Mr. Blakesley thought the energy that returns to the oscillator would be available for subsequent radiations.

Dr. Lodge pointed out that wires or other resonators placed within the quarter wave-length would intercept part of the returning energy.

IV. On Certain Relations existing amongst the Refructive Indices of some of the Chemical Elements. By the Rev. Pelnam Dalx, M.A. (Abstract.)

TaE paper contained calculations published by the author last year, supplemented with fresh data obtained from Muir's 'Principles of Chemistry.'

V. Additional Notes on Secondary Batteries. By Dr. J. H. GLAdSTONE, F.R.S., and W. HibBert, F.I.C.

During the publication of a series of papers by Dr. Gladstone and Mr. Tribe in 'Nature,' 1882, on the "Chemistry of the Planté and Faure Accumulators," a discussion arose as to whether the sulphate of lead, to which they attributed so important a part in the reaction, could be reduced by electrolysis. It was shown at the time by experimental proof that this was possible, even when the sulphate of lead was pure, and it was contended that when intimately

* Read November 28, 1800. 
mixed with peroxide of lead, as in actual practice, there was no difficulty about the matter *

There arose, however, a belief that a subsulphate of lead was produced on the plates. Some experimenters found in this belief an explanation of the difficulty in reducing those masses of salt which occasionally form in practice, while others looked upon the subsalt as more easily reducible than the neutral compound.

So far as we are aware, no specimen of the supposed subsalt was described till Profesşor Frankland published his paper in the Royal Society's Proceedings, 1889 , vol. xlvi. p. 304, in which he gives an account of what he believes to be two definite subsulphates. That produced from litharge we have already examined in our paper of last June $\dagger$. Since then we have turned our attention to the other possible subsalt made by the action of sulphuric acid on minium.

In the original paper $\neq$, Gladstone and Tribe gave the formula of decomposition as

$$
\mathrm{Pb}_{8} \mathrm{O}_{4}+2 \mathrm{H}_{2} \mathrm{SO}_{4}=\mathrm{PbO}_{2}+2 \mathrm{PbSO}_{4}+2 \mathrm{H}_{2} \mathrm{O} \text {. }
$$

They showed by means of a quantitative experiment its gradual slow formation, and said, "It is evident that in a Faure battery we are dealing with plates that consist of a superficial layer of mixed peroxide and sulphate of lead."

Frankland, while viewing this red substance as a sub. sulphate, arrived at precisely the same ultimate composition, which he expressed by the formula $\mathrm{S}_{2} \mathrm{~Pb}_{3} \mathrm{O}_{10}$. $\mathrm{He}$ adduces, however, no evidence to show that it is not a mixture of $\mathrm{PbO}_{2}$ with $2 \mathrm{PbSO}_{4}$. We sought for some means of deciding between these two views. A solution of acetate of ammonium is known to dissolve sulphate of lead, and was in fact used long ago for that purpose. It might therefore be expected to separate the sulphate from the peroxide, while it was not so likely to bring about the decomposition of such a compound as $\mathrm{S}_{2} \mathrm{~Pb}_{3} \mathrm{O}_{10}$.

* See "The Chemistry of the Secondary Batteries" in 'Nature' Series.

† Phil. Mag. Aug. 1890 , and Proc. Phys. Soc. x. p. 448.

$\ddagger$ See volume cited, p. 14. 
Some of the red substance was prepared by treating minium with an excess of dilute sulphuric acid ( 1 of acid to 10 of water). After four days the action was still incomplete, but eventually it absorbed the full amount of acid required by theory.

The percentage of lead in the resulting red substance was just over 72 per cent.

A portion of this, after treatment with a 3 per cent. solution of acetate of ammonium, left a residue which was much darker in colour than the original and contained 82 per cent. of lead. That is to say, it was approximating towards $\mathrm{PbO}_{2}$, which contains $86^{\circ} 6$ per cent. of lead. The liquid was colourless, and the ratio between the $\mathrm{Pb}$ and $\mathrm{SO}_{4}$ dissolved was determined in several different instances. The ratio

$$
\text { Weight of } \mathrm{Pb}
$$

varied from $2 \cdot 0$ to $2 \cdot 15$, pure $\mathrm{PbSO}_{4}$ requiring $2 \cdot 16$ and Frankland's compound $3 \cdot 23$. The portion dissolved therefore was not a basic sulphate, and the evidence tells against the original substance being a chemical compound.

Of course, it is impossible to affirm that no subsulphate is ever formed in the reactions of a secondary cell, but all that we actually know is perfectly consistent with the old and simpler supposition that $\mathrm{PbSO}_{4}$ is the salt alternately formed and decomposed.

\section{Action of Sulphuric Acid on Lead.}

In our former communication we described a comparative. experiment in which dilute sulphuric acid, either alone or mixed with a small quantity of sodium sulphate, was allowed to act on spongy lead. The experiment was allowed to continue 'for five months, and hydrogen gas was given off for such a length of time that we thought it would be interesting to analyse the resulting substance.

The residue from the action of the pure acid on the lead consisted of 82 per cent. of sulphate of lead and 18 per cent. of metallic lead, while that from the action of acid mixed with 
sulphate of soda consisted of 89 per cent. of lead sulphate and 11 per cent. of metallic lead.

Although the action of the acid on the lead was initially diminished by the presence of sodium sulphate, the final result in this instance was rather the other way. No doubt the whole of the spongy lead would have been converted into sulphate if it had not been for the large amount of insoluble salt which protected the remaining particles.

This result throws light on the reason why a lead plate deteriorates during a long rest.

VI. A Lecture Experiment illustrating the Effect of Heat upon the Mugnetic Susceptibility of Nickel. By SHELFORD BIDwELL, M.A., F.R.S.*

IT is well known that iron when made red-hot loses its susceptibility and practically becomes a non-magnetic metal. Nickel becomes non-magnetizable at a much lower temperature, perhaps at about $300^{\circ}$. The following is a description of a simple piece of apparatus by means of which this effect may be shown as a lecture experiment.

A copper disk, to which a thin projecting tongue of nickel is soldered, hangs like the bob of a pendulum from a double thread. This bob is held on one side by a horizontally-fixed bar-magnet, which attracts and holds fast the nickel tongue when brought into contact with it. A spirit-lamp is placed beneath the tongue, and in a few seconds the heat of the flame temporarily destroys the magnetic quality of the nickel, so that the magnet can no longer hold it. The bob accordingly falls back and performs an oscillation. In. the course of its excursion, however, the metal becomes cooler, and when it returns to the neighbourhood of the magnet the tongue is once more attracted. But after a momentary contact it is again liberated, and the process is repeated. If the position of the magnet and the size of the flame are properly adjusted, and care is taken to shield the apparatus from

* Read April 13, 1889. 